\title{
Abdominal Epilepsy in Gov. Celestino Gallares Memorial Hospital
}

\author{
Ma. Kahra Christy E. Jumawan ${ }^{1}$, Anabella A. Salise-Oncog ${ }^{2}$, Edgardo B. EPE \\ 1 Purok Morning Star, Brgy. Olingan, Dipolog City, Zamboanga del Norte, Philippines \\ 2 Department of Pediatrics, Gov. Celestino Gallares Memorial Hospital, Janssen Heights, Dampas District, Tagbilaran City, Bohol 6300, \\ Philippines \\ 3 Department of Pediatrics, Governor Celestino Gallares Memorial Hospital, M. Parras St., Tagbilaran City, Bohol, Philippines
}

*Corresponding Author: Dr. Anabella S. Oncog, Department of Pediatrics, Gov. Celestino Gallares Memorial Hospital, Janssen

Heights, Dampas District, Tagbilaran City, Bohol 6300, Philippines.

Email: abelle salise@yahoo.com, abelle salise@icloud.com

Received: January 24, 2020; Accepted: March 10, 2020

\begin{abstract}
Abdominal epilepsy is an uncommon cause of recurrent vomiting in children and in adults. We report a case of an 8-year old girl who has had frequent admissions for recurrent vomiting accompanied by headache and odd behaviors. Her physical examination findings were normal. Hematologic, radiologic and ultrasound findings were normal. The electroencephalogram showed epileptiform discharges in frontocentral regions. She responded well to phenobarbital.
\end{abstract}

Keywords: Seizure, Abdominal Epilepsy, Iran.

\section{INTRODUCTION}

Abdominal epilepsy is a rare condition that presents with manifestations often not attributed to the central nervous system. Patients with this condition presents with gastrointestinal manifestations and neurologic findings that are brought about by epileptiform seizure activity $[1,2]$. Because of its varied symptomatology, the diagnosis of abdominal epilepsy is challenging and is usually made late in the course of the condition.

Although abdominal epilepsy is reported to be more common in children than in adults, the number of reported cases worldwide has been sparse. To the best of our knowledge, there has been no case of abdominal epilepsy reported yet in the Philippines.

\section{CASE REPORT}

This was the case of an 8-year old girl who was admitted for vomiting to our institution, Gov. Celestino Gallares Memorial Hospital. The history of present illness showed that the vomiting was associated with headache, epigastric pain, and aphasia, as well as lethargy after vomiting. The past medical history revealed that she has had a total of 14 admissions since she was 5 years old; all admissions were for vomiting associated with the above symptoms. She has been treated as a case of non-ulcer dyspepsia and has been given antacids and/or H2-blockers. The symptoms usually resolved within a week. There was no history of epilepsy in the family. The personal and social history revealed that she has been dropped from the honor roll in school because of absenteeism from frequent hospital admissions. She was also seen to manifest social withdrawal and preferred the company of her mother than that of a schoolmate; her mother claimed that she had no friend.

The physical examination during this admission was normal but she was found to be uncooperative and aphasic on neurologic examination. She did not speak nor follow instructions. She was initially diagnosed with cyclic vomiting syndrome and was worked up. The complete blood count, electrolyte levels, abdomen radiograph and ultrasound were all normal.

In the ward, she was noted to present with odd behavior. Aside from being aphasic, she was restless and was showing her genitals. She was given a dose of diazepam which relieved the symptoms. She became interactive and composed after administration of diazepam. An electroencephalogram was requested as outpatient because it was not available in our hospital. She was discharged with a prescription of Topiramate as therapeutic trial; however, this was not complied with because the mother wanted to have the EEG first.

The patient was again admitted 4 days after discharge from the hospital because of the same symptoms: vomiting, headache, epigastric pain, and odd behavior. This time, she was given Phenobarbital, which immediately relieved the symptoms. She was discharged improved with Phenobarbital as home medication.

The EEG was done in another hospital and showed epileptiform discharges over both frontocentral regions. Thus, the diagnosis 
of abdominal epilepsy was clinched.

\section{DISCUSSION}

Abdominal epilepsy is an uncommon cause of recurrent vomiting in children and in adults. It was first described by the French scientist and physician, Armand Trosseau, in a boy who had paroxysmal Gl symptoms that culminated in grand mal epileptic seizures in 1868 [3]; but the first account of EEG-supported abdominal epilepsy was reported by Matthew Moore in 1944 [4].

There is a scarcity of reported cases of abdominal epilepsy worldwide. In 2005 , there were only 36 cases of abdominal epilepsy that were reported [5]. In 2009, a case report in Nigeria presented a case of abdominal epilepsy in a 4-year old girl [6]. In 2014, a pediatric case series conducted in India added 6 more cases of abdominal epilepsy [7]. Our case adds one more to the list.

To date, the exact pathophysiology of abdominal epilepsy is unknown, but the most commonly seen underlying pathology is hippocampal sclerosis which is associated with febrile convulsions and subsequent development of complex partial seizures in late childhood or adolescence [8]. Other possible etiologies included temporal lobe tumors, malformations, bilateral perisylvian polymicrogyria, febrile seizures, neuroendocrine dysfunction, and prematurity [9].

The diagnosis of abdominal epilepsy is based on the following criteria: (1) paroxysmal gastrointestinal complaints that are otherwise unexplained; (2) manifestations of central nervous system disturbance; (3) an abnormal electroencephalogram compatible for a seizure disorder; and (4) improvement with anticonvulsant medication $[5,9,10]$.

Gastrointestinal manifestations may include abdominal pain, vomiting, nausea, abdominal bloating or diarrhea, but the most common of these are abdominal pain and vomiting1. Cyclic vomiting is a close differential to abdominal epilepsy, but the presence of abnormal electroencephalogram differentiates abdominal epilepsy from cyclic vomiting. Interestingly, there are at least 2 medical articles that reported that cyclic vomiting may be a manifestation of abdominal epilepsy $[11,12]$. This may be the case in our patient.

Manifestations of CNS disturbance may include confusion, lethargy, fatigue, headache, dizziness, syncope, convulsions or unresponsiveness, but the most common of these are confusion and lethargy [6].

Because of the diverse presentations, abdominal epilepsy can be either masked or misdiagnosed as a physical or psychological disorder. Our patient has been diagnosed with dyspepsia. Öztürk, et al, reported a case of a 16-year old with abdominal epilepsy who was previously managed as conversion disorder [13]. Another child with abdominal epilepsy was misdiagnosed to have psychogenic pain [14].

An abnormal electroencephalogram that is specific for a seizure disorder supports the diagnosis of abdominal epilepsy. The most common EEG findings in patients with abdominal epilepsy are bursts of sharp waves and/or spikes from one or both temporal regions $[9,10]$. Other EEG findings that were reported were generalized spike and wave discharges, and right frontal focal discharge with generalization [1]. Our patient presented with epileptiform discharges over both frontocentral regions.
The benefit of an EEG in the diagnosis of abdominal epilepsy cannot be overemphasized. Without it, the diagnosis of abdominal epilepsy could not be confirmed. The lack of EEG is probably one of the reasons why there is a paucity in reported cases of abdominal epilepsy.

A positive response, together with an abnormal EEG, clinches the diagnosis of abdominal epilepsy. However, there has been no recommendation yet on the choice of anticonvulsant to use10. Existing case reports on abdominal epilepsy have used oxcarbazepine, phenytoin or valproate $[1,15,16]$. There has been no published report yet on the use of phenobarbital in abdominal epilepsy. Our patient responded favorably to phenobarbital. Phenobarbital would be advantageous because it is cheaper compared to other anticonvulsants.

A high index of suspicion should be maintained in order to diagnose abdominal epilepsy. An electroencephalogram should be performed. Phenobarbital may be an effective anticonvulsant for abdominal epilepsy.

\section{Conflict of Interest}

We declare that we have no conflict of interest.

\section{Financial Support}

None declared.

\section{REFERENCES}

1. Dutta SR, Hazarika I, Chakravarty BP. Abdominal epilepsy, an uncommon cause of recurrent abdominal pain: a brief report. Gut. 2007 Mar 1;56(3):439-41.

2. Mpondo BC, Mwasada G, Nyundo AA. Abdominal epilepsy, an uncommon cause of chronic and recurrent abdominal pain: a case report. Clinical case reports. 2016 Dec;4(12):1117.

3. Agrawal P, Dhar NK, Bhatia MS, Malik SC. Abdominal epilepsy. The Indian Journal of Pediatrics. 1989 Jul 1;56(4):539-41.

4. Moore MT. Paroxysmal abdominal pain: a form of focal symptomatic epilepsy. Journal of the American Medical Association. 1944 Feb 26;124(9):561-3.

5. Zinkin NT, Peppercorn MA. Abdominal epilepsy. Best Practice \& Research Clinical Gastroenterology. 2005 Apr 1;19(2):263-74.

6. Ashir GM, Alhaji MA, Gofama MM, Ibrahim AB, Azuka NC. Abdominal epilepsy in a Nigerian child. South African Journal of Child Health. 2009;3(3):96-97.

7. Mondal R, Sarkar S, Bag T, Mondal K, Saren A. A pediatric case series of abdominal epilepsy. World Journal of Pediatrics. 2014 Feb 1;10(1):80-2.

8. Topno N, Gopasetty MS, Kudva A. Abdominal epilepsy and foreign body in the abdomen-dilemma in diagnosis of abdominal pain. Yonsei medical journal. 2005 Dec 31;46(6):870-3.

9. Franzon RC, Lopes CF, Schmutzler KM, Morais MI, Guerreiro MM. Recurrent abdominal pain: when an epileptic seizure should be suspected? Arquivos de neuro-psiquiatria. 2002 Sep;60(3A):628-30.

10. Peppercorn MA, Herzog AG. The spectrum of abdominal epilepsy in adults. American Journal of Gastroenterology. 1989 Oct 1;84(10):1294-96.

11. Mitchell WG, Greenwood RS, Messenheimer JA. Abdominal epilepsy: Cyclic vomiting as the major symptom of simple partial seizures. Archives of neurology. 1983 Apr 1;40(4):251-2.

12. Millichap JG, Lombroso CT, Lennox WG. Cyclic vomiting as a form of epilepsy in children. Pediatrics. 1955 Jun 1;15(6):705-14.

13. Öztürk Y, Göl G, Savcı U, Cansız MA, Tufan AE. Abdominal 
epilepsy mimicking conversion disorder: a case report. Psychiatry and Clinical Psychopharmacology. 2019 Oct 2;29(4):484-6.

14. Singhi PD, Kaur S. Abdominal epilepsy misdiagnosed as psychogenic pain. Postgraduate medical journal. $1988 \mathrm{Apr}$ 1;64(750):281-2.

15. Kshirsagar VY, Nagarsenkar S, Ahmed M, Colaco S, Wingkar KC. Abdominal epilepsy in chronic recurrent abdominal pain. Journal of pediatric neurosciences. 2012 Sep;7(3):163-66.

16. Yunus Y, Sefer U, Dondu UU, Ismail O, Yusuf E. Abdominal epilepsy as an unusual cause ofabdominal pain: A case report. African health sciences. 2016;16(3):877-9. 